\title{
Deposition of Amorphous and Crystalline Al doped ZnO Thin Films by RF Magnetron Sputtering and their Comparative Properties
}

\author{
Pankaj K. Bhujbal, Habib M. Pathan and Nandu B. Chaure*
}

Transparent and highly conducting amorphous and crystalline $\mathrm{Al}$ doped $\mathrm{ZnO}$ thin films were grown on glass substrate at room temperature by $\mathrm{RF}$ magnetron sputtering. The structural, electrical, morphological and optical properties of amorphous and crystalline $\mathrm{Al}$ doped $\mathrm{ZnO}$ thin films were studied. The XRD pattern revealed that the crystalline film corresponds to hexagonal wurtzite structure with (002) preferred orientation. The minimum resistivity $4.2 \times 10^{-3} \Omega \mathrm{m}$ was observed for crystalline film. The AFM and transmission spectra show that the average roughness of the crystalline film is higher than that of the amorphous film. Photoluminescence spectrum shows band to band transition in UV region and defect related transitions peaks in visible region. The deposited crystalline film shows low optical bandgap, $3.32 \mathrm{eV}$ than amorphous film, 3.51 $\mathrm{eV}$.

Keywords: Amorphous; Al doped ZnO; XRD; RF Power; Ar gas flow

Received 23 November 2018, Accepted 15 January 2019

DOI: $10.30919 / \mathrm{esee} 8 \mathrm{c} 188$

\section{Introduction}

The transparent conducting oxides (TCO) are widely studied because of their unique and useful properties like high transparency as well as conductivity. The demand of TCO material goes on increasing due to its interesting applications in photovoltaic solar cell, flat panel display, liquid crystal display and wave guides in plasmonic device. ${ }^{1}$ The ITO (indium tin oxide) is the most effective TCO material for electronics and optical applications, because of its high conductivity and transparency in visible region. However, issues arises with ITO due to the low natural abundance of indium. Hence, it is necessary to find alternative to ITO, which is having large availability, high transparency, high conductivity and low cost. $\mathrm{Al}$ doped $\mathrm{ZnO}$ is the most promising material for many applications like counter electrode, sensors, optoelectronics, LCD etc. Because it has wide optical bandgap $3.37 \mathrm{eV}$, at room temperature, high mechanical, electrical and thermal stability, high transparency in whole visible region, highly conducting with large exciton binding energy $60 \mathrm{meV}^{2}$ Numerous methods have been employed to prepare $\mathrm{Al}$ doped $\mathrm{ZnO}$ thin films such as pulsed laser deposition, ${ }^{3}$ sol-gel, RF magnetron sputtering, ${ }^{4}$ spray pyrolysis ${ }^{5}$ and chemical vapor deposition. Among those RF sputtering is one of most efficient, easy and low cost techniques for the preparations of $\mathrm{Al}$ doped $\mathrm{ZnO}$ thin films, which produce well crystalline, high surface area and adhesive thin films and film deposition take place at room temperature as well. ${ }^{6}$ In the present work, deposition of amorphous and crystalline Al doped $\mathrm{ZnO}$ films has been carried out using $\mathrm{RF}$ magnetron sputtering and their structural, optical, morphological and electrical properties has been studied with comparison.

Department of Physics, Savitribai Phule Pune University, Pune411007, India

*E-mail: n.chaure@physics.unipune.ac.in

\section{Experimental and Characterization}

The amorphous and crystalline $\mathrm{Al}$ doped $\mathrm{ZnO}$ thin films were deposited by RF magnetron sputtering consisting of (99.99\% purity, $76.2 \mathrm{~mm}$ diameter, $3 \mathrm{~mm}$ thickness, $\mathrm{Al}_{2} \mathrm{O}_{3}: \mathrm{ZnO}=2: 98$ wt \%) $\mathrm{Al}$ doped $\mathrm{ZnO}$ ceramic target. The cleaned glass substrate was placed at the center of the subtract holder inside the sputtering chamber. The chamber was evacuated to a base pressure of $<10^{-5}$ Torr by a turbo molecular pump. The amorphous $\mathrm{Al}$ doped $\mathrm{ZnO}$ film was deposited at $100 \mathrm{~W}$ RF power, keeping Ar gas flow rate at $80 \mathrm{sccm}$ and deposition was carried out for 15 minutes at room temperature. Similarly, the crystalline Al doped $\mathrm{ZnO}$ film was deposited using above mentioned parameters at $200 \mathrm{~W}$ RF power. The optical, micro structural, morphological and electrical properties of the amorphous and crystalline $\mathrm{Al}$ doped $\mathrm{ZnO}$ thin films were studied systematically. The transmission and absorption spectra were measured with optical JASCO V-770 UV-Vis spectrophotometer. Perkin Elmer LS-55 photoluminescence spectrometer was used to study photoluminescence spectra. The micro structural properties of amorphous and crystalline $\mathrm{Al}$ doped $\mathrm{ZnO}$ films were studied using $\mathrm{X}$ ray diffractometer, model Bruker D8 with $\mathrm{Cu} \mathrm{K \alpha}$ radiation of wavelength $1.5405 \mathrm{~A}^{\circ}$ to investigate the crystallinity, crystallite size and crystal orientation. The surface morphology of as-deposited amorphous and crystalline $\mathrm{Al}$ doped $\mathrm{ZnO}$ films were studied by using atomic force microscope. The resistivity, carrier concentration and mobility of the $\mathrm{Al}$ doped $\mathrm{ZnO}$ thin films were measured by using Hall measurement system using Van der pauw technique.

\section{Results and Discussion}

\subsection{Micro Structural Properties}

Fig. 1 shows X-ray diffraction spectra corresponding to the amorphous and crystalline $\mathrm{Al}$ doped $\mathrm{ZnO}$ thin films. To study structural properties of amorphous and crystalline $\mathrm{Al}$ doped $\mathrm{ZnO}$ thin films, $\mathrm{XRD}$ was used 


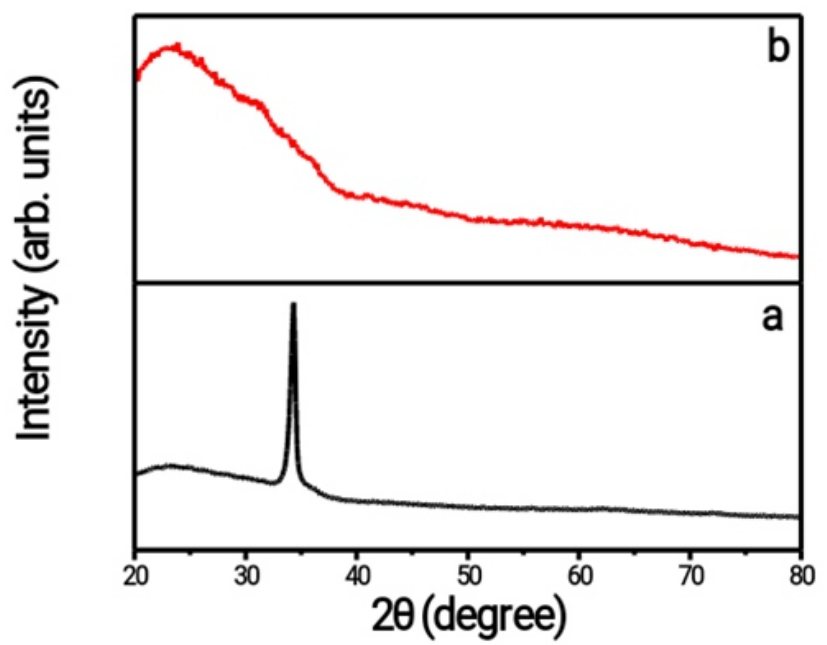

Fig. 1 XRD pattern of as-deposited (a) amorphous and (b) crystalline $\mathrm{Al}$ doped $\mathrm{ZnO}$ films.

in the 20-80 degree $2 \theta$ range. From XRD, it is observed that there is less deposition and growth at low RF power $(100 \mathrm{~W})$, hence the sample is amorphous in nature. Increase in RF power increases kinetic energy and mobility of sputtered particles on the surface of $\mathrm{Al}$ doped $\mathrm{ZnO}$ films. Highly energetic particles can migrate to more appropriative lattice sites and adjust their bond length to optimum bonding to the adjacent ones, which are helpful for nucleation and growth of the film. The crystalline growth of the layer can also be associated to the nucleation and growth of thim film. ${ }^{7}$ The crystal structure of crystalline Al doped $\mathrm{ZnO}$ film was associated to a c-axis (002) oriented wurtzite type hexagonal structure. ${ }^{8}$ The crystalline $\mathrm{Al}$ doped $\mathrm{ZnO}$ film shows preferred orientation along (002) plane may be due to the minimization of the internal stress of the crystal plane of the film. The crystallite size $22.6 \mathrm{~nm}$ of the crystalline $\mathrm{Al}$ doped $\mathrm{ZnO}$ film was calculated by using Scherer's formula as equation (1),

$$
\mathrm{D}=\frac{0.9 \lambda}{\beta \cos \theta}
$$

where $\lambda, \theta, \beta$ and $\mathrm{D}$ is the wavelength of the $\mathrm{X}$-ray, Bragg diffraction angle, full width half maximum of the peak and average crystallite size of the $\mathrm{Al}$ doped $\mathrm{ZnO}$ films.

\subsection{Morphological Properties}

The surface roughness and surface topography were studied using atomic force microscopy. Fig. 2 (a) and (b) show AFM images of amorphous and crystalline $\mathrm{Al}$ doped $\mathrm{ZnO}$ thin films. Both the amorphous and crystalline films show very uniform and densely packed surface morphology. The particle size approximately 200 to $400 \mathrm{~nm}$ can be seen for the amorphous $\mathrm{Al}$ doped $\mathrm{ZnO}$ sample. The improvement in the particle size approximately 500 to $700 \mathrm{~nm}$ is observed for the crystalline $\mathrm{Al}$ doped $\mathrm{ZnO}$ sample. The increased particle size of the crystalline film can be due to the releasing of more atoms, during sputter deposition at high RF power $(200 \mathrm{~W})$. The large clusters observed in Fig. 2 (b) are formed by the agglomeration of small grains. Average roughness for amorphous and crystalline $\mathrm{Al}$ doped $\mathrm{ZnO}$ films were $7.16 \mathrm{~nm}$ and $7.78 \mathrm{~nm}$ respectively. The formation of a textured surface with pyramidal structures gives the higher roughness to crystalline film.

\subsection{Optical Properties}

The transmission and absorption spectra of the amorphous and crystalline $\mathrm{Al}$ doped $\mathrm{ZnO}$ thin films are shown in Fig. 3 (A) and (B), respectively.

The crystalline $\mathrm{Al}$ doped $\mathrm{ZnO}$ film shows $98.6 \%$ transparency in visible region. The transmission of deposited crystalline film show lower transparency than amorphous film, it may be due to high roughness of the crystalline film which increase the optical scattering. ${ }^{10}$ The absorption curve shown in Fig. 2 (B) revealed that the absorption increases for the crystalline sample, this could be because of scattering of incident light at grain boundaries or due to rough surface. This result is in good agreement with the AFM results. The increased absorption could also be due to increase in thickness of the sample. The fundamental absorption edge is red shifted for the crystalline sample. This shift could be associated to the increased particle size. The optical band gap of both the film is determined using the Tauc equation (2),

$$
\alpha h v=\mathrm{A}\left(\mathrm{h} v-\mathrm{E}_{\mathrm{g}}\right)^{2}
$$

where, $\mathrm{E}_{\mathrm{g}}$ is the optical band gap, hv is the incident photon energy and A is the constant. The inset of Fig. 2 (B) shows the tauc plot of the amorphous and crystalline sample respectively. The energy band gaps of amorphous and crystalline samples are 3.51 and $3.32 \mathrm{eV}$. Crystalline
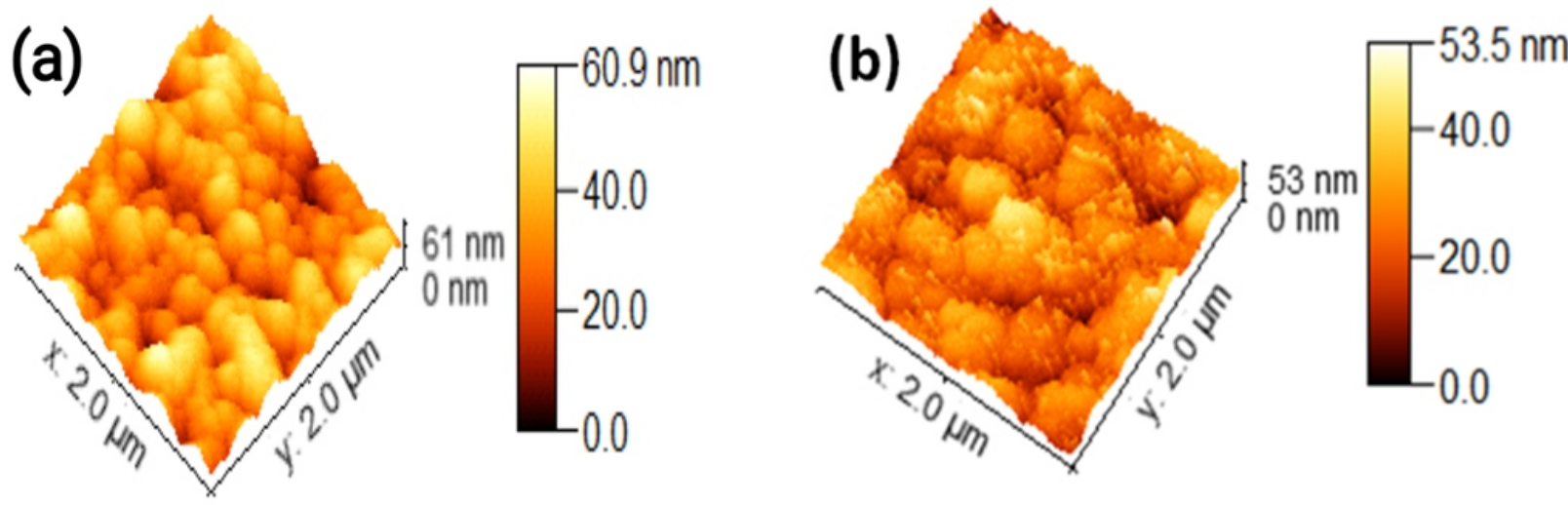

Fig. 2 AFM images of (a) amorphous (b) crystalline $\mathrm{Al}$ doped $\mathrm{ZnO}$ films. 

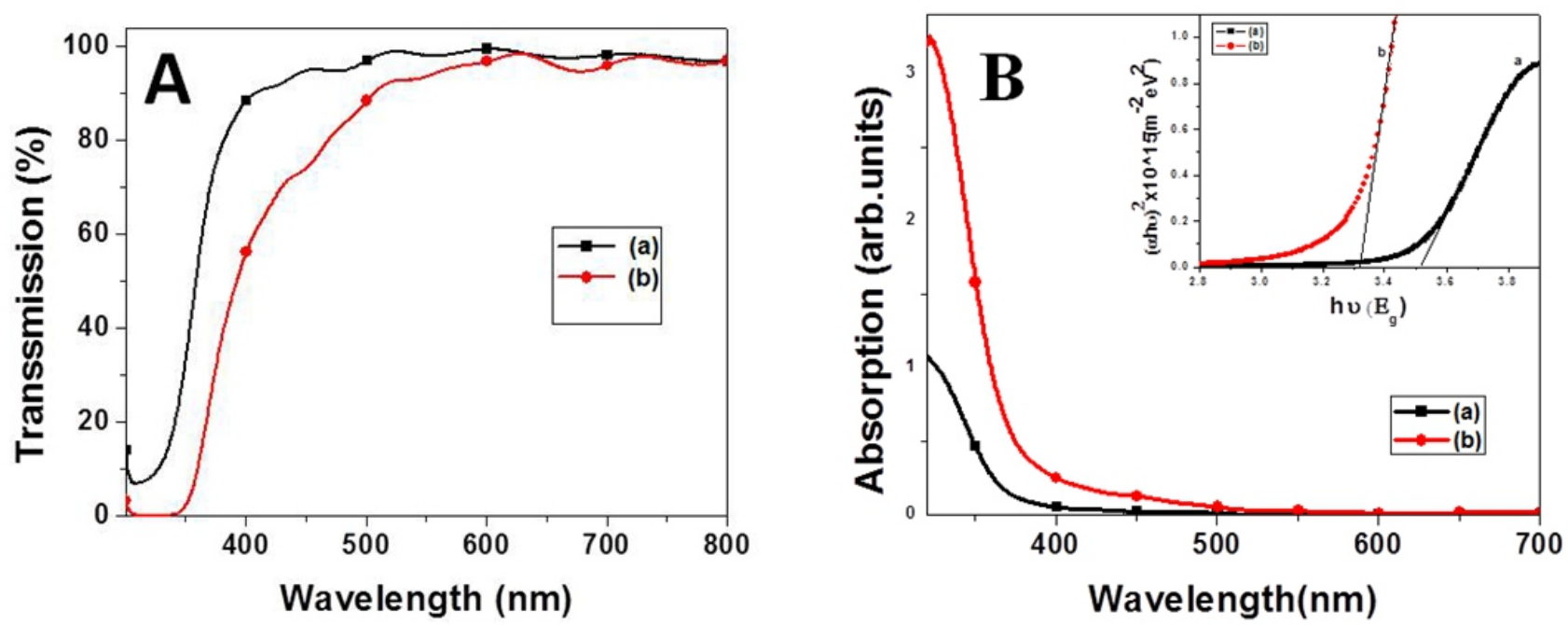

Fig. 3 (A) Transmission spectra of the (a) amorphous and (b) crystalline Al doped $\mathrm{ZnO}$ thin films and (B) Absorbance of the (a) amorphous and (b) crystalline $\mathrm{Al}$ doped $\mathrm{ZnO}$ thin films, inset shows the Tauc plot.

film shows lower band gap than amorphous film due to the increasing thickness as well as the crystallite size of the $\mathrm{Al}$ doped $\mathrm{ZnO}$ films as a result of confinement effect. ${ }^{8}$ Thicknesses of both the $\mathrm{Al}$ doped $\mathrm{ZnO}$ films were calculated by using fringes observed in transmission spectra of both the films. The film thickness 500 and $700 \mathrm{~nm}$ were observed for the amorphous and crystalline films respectively. Enhancement in film thickness may be due to the increase in crystallite size of the sample. Above result is well consistent with transmission spectra and XRD results.

Photoluminescence spectra of the amorphous and crystalline $\mathrm{Al}$ doped $\mathrm{ZnO}$ thin films were studied to reveal the electronic structure and defect related transitions at room temperature. Fig. 4 shows the Photoluminescence (PL) spectra of the amorphous and crystalline $\mathrm{Al}$ doped $\mathrm{ZnO}$ thin films at room temperature. Photoluminescence spectra of the amorphous and crystalline $\mathrm{Al}$ doped $\mathrm{ZnO}$ thin film obtained with the excitation wavelength of $280 \mathrm{~nm}$. The emission peaks were attributed around $401 \mathrm{~nm}$ (UV emission), $419 \mathrm{~nm}$ (violet emission), 447 $\mathrm{nm}$ (violet-blue emission), $481 \mathrm{~nm}$ (blue emission), $535 \mathrm{~nm}$ (green emission) and $399 \mathrm{~nm}$ (UV emission), $418 \mathrm{~nm}$ (violet emission), 479 $\mathrm{nm}$ (blue emission), $535 \mathrm{~nm}$ (green emission) for the crystalline and amorphous films respectively. It represents emission due to impurity or defects present in the film. The emission peak observed at 401 and 399 $\mathrm{nm}$ for the crystalline and amorphous $\mathrm{Al}$ doped $\mathrm{ZnO}$ films respectively, are associated to the band to band transition, and are also known as near band edge transition (NBE). It may be arises due to free exciton recombination and depend on the crystallinity of the film. ${ }^{12}$ The PL spectra shows that the photoluminescence intensity of crystalline film is greater than those of amorphous film, it may be due to the crystallinity of the crystalline film is greater than amorphous film. This result is very well consistent with XRD result.

The emission peaks $\mathrm{E}_{2}$ and $\mathrm{F}_{2}$ at $419 \mathrm{~nm}$ and $418 \mathrm{~nm}$ are considered as a violet emission peaks. It may be due to zinc interstitial $\left(\mathrm{Zn}_{\mathrm{i}}\right)$ in the interface traps at the grain boundaries of $\mathrm{Al}$ doped $\mathrm{ZnO}$ thin films. ${ }^{11}$ The emission peaks $E_{3}$ and $F_{3}$ observed at $481 \mathrm{~nm}$ and $479 \mathrm{~nm}$ for crystalline and amorphous films respectively, are considered as blue emission peaks. It may be due to transitions from zinc inertial to zinc

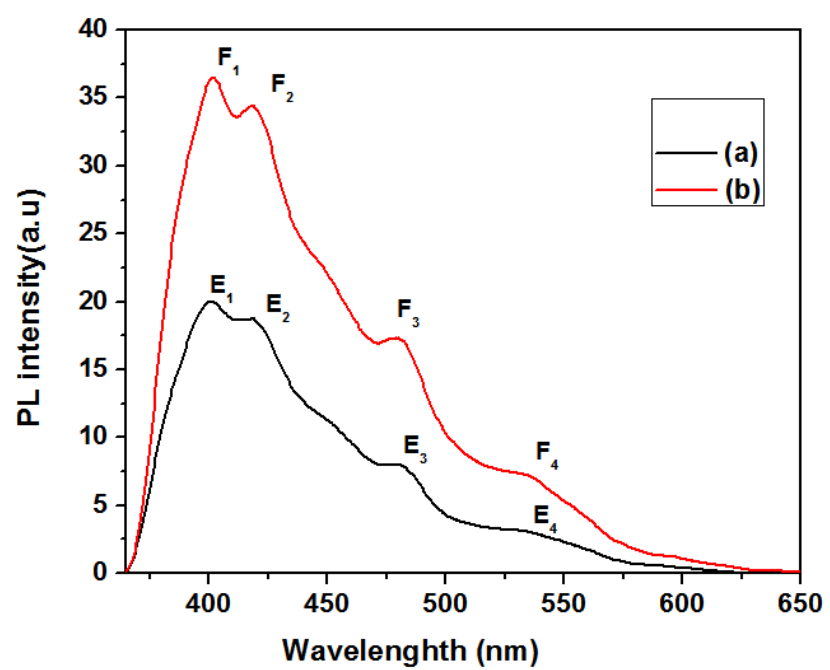

Fig. 4 PL spectra of the (a) amorphous and (b) crystalline Al doped $\mathrm{ZnO}$ films.

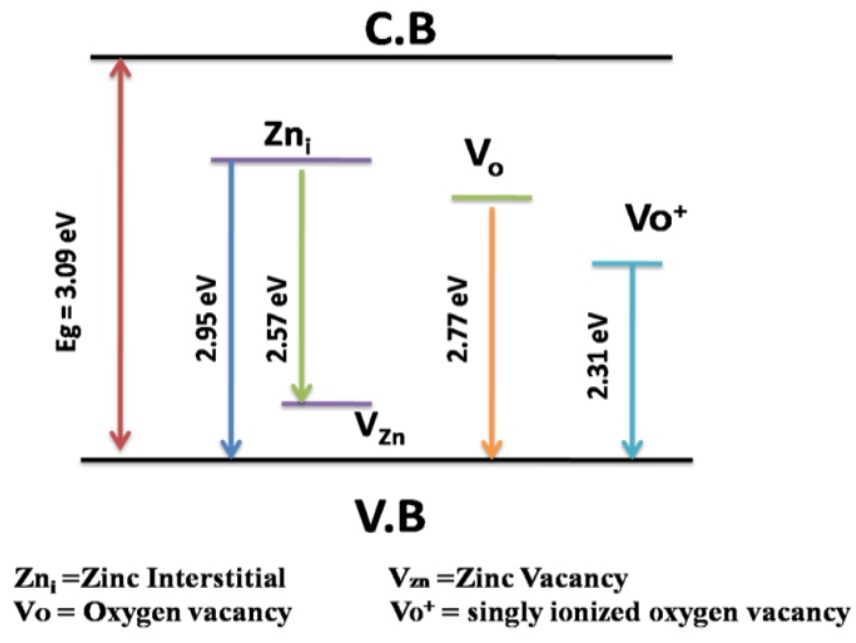

Fig. 5 Schematic representation of defect levels in $\mathrm{Al}$ doped $\mathrm{ZnO}$ thin films. 
vacancy $\mathrm{Zn}_{\mathrm{i}} \rightarrow \mathrm{V}_{\mathrm{m} \cdot{ }^{12}}$

The emission peaks observed around $535 \mathrm{~nm}$ is related to green line emission. The radial recombination of photo generated hole with electron of singly ionized charged particles is responsible for green emission peak. ${ }^{13}$ Those peaks represent the presence of $\mathrm{V}_{0}^{+}$defects in both amorphous and crystalline $\mathrm{Al}$ doped $\mathrm{ZnO}$ films. Fig. 5 shows the schematic representation of defect level with possible transitions responsible for various photoemissions in amorphous and crystalline $\mathrm{Al}$ doped $\mathrm{ZnO}$ thin films.

\subsection{Electrical Properties}

The electrical resistivity, carrier concentration and mobility of the amorphous and crystalline $\mathrm{Al}$ doped $\mathrm{ZnO}$ thin films were measured by using Hall measurement system. The electrical resistivity ( $\rho$ ), Hall mobility $(\mu)$ and carrier concentration (n) were $2.13 \times 10^{-2} \Omega \mathrm{m}, 0.79$ $\mathrm{m}^{2} / \mathrm{Vs}$ and $3.6 \times 10^{14} \mathrm{~m}^{-3}$ and $4.2 \times 10^{-3} \Omega \mathrm{m}, 0.15 \mathrm{~m}^{2} / \mathrm{Vs}$ and $9.7 \times 10^{15} \mathrm{~m}^{-3}$ for the amorphous and crystalline $\mathrm{Al}$ doped $\mathrm{ZnO}$ films respectively. The crystalline $\mathrm{Al}$ doped $\mathrm{ZnO}$ film shows low resistivity than amorphous, which can be attributed to the increase of grain size. Increased grain size reduces the grain boundary scattering, resulting in higher conductivity of the crystalline film than amorphous film. Above result is consistent with AFM results.

\section{Conclusion}

The transparent and highly conducting amorphous and crystalline Al doped $\mathrm{ZnO}$ thin films have been successfully grown by RF sputtering technique. XRD data revealed that there is less deposition and growth at low RF power $(100 \mathrm{~W})$, hence the sample is amorphous in nature, and the film deposited at $200 \mathrm{~W}$ RF power exhibits crystallinity along caxis (002) orientation and shows hexagonal wurtzite crystal structure. The morphological and optical investigation revealed that the average roughness and film thickness of the crystalline film is greater than amorphous film. The reduction in optical band gap of crystalline sample is due to increase in thickness as well as the crystallite size as a result of confinement effect. Photoluminescence spectra show the defect related transitions peaks in visible region. The electrical investigation revealed that the crystalline $\mathrm{Al}$ doped $\mathrm{ZnO}$ film achieved minimum resistivity i.e. $4.2 \times 10^{-3} \Omega \mathrm{m}$.

\section{Acknowledgement}

Authors are thankful to Department of Science and Technology, New Delhi for financial support under Solar Energy Research Initiative scheme.

\section{References}

1. Z. A. Wang, J. B. Chu, H. B. Zhu, Z. Sun, Y. W. Chen, and S. M. Huang, Solid State Electron., 2009, 53, 1149-1153.

2. S. C. Dixon, D. O. Scanlon, C. J. Carmalt, and I. P. Parkin, J. Mater. Chem. C, 2016, 4, 6946-6961.

3. G. Kaur, A. Mitra, and K. L. Yadav, Prog. Nat. Sci. Mater. Int., 2015, 25, $12-21$.

4. T. Minami, H. Nanto, S. Shooji, and S. Takata, Thin Solid Films, 1984, 111, 167-174.

5. M. Caglar, S. Ilican, Y. Caglar, and F. Yakuphanoglu, J. Mater. Sci. Mater. Electron., 2008, 19, 704-708.

6. L. Wen, M. Kumar, H. J. Cho, K. Leksakul, and J. G. Han, J. Phys. D Appl. Phys., 50(18).

7. R. G. Waykar, J. Mater. Sci. Mater. Electron., 2016, 27, 1134-1143.

8. N. Srinatha, RSC Adv., 2016, 6, 9779-9788,

9. A. Barhoumi, G. Leroy, L. Yang and J. Gest, J. Appl. Phys., 2014, 115, 204502-1-204502-7

10. H. Kong, P. Yang, and J. Chu, J. Phys. Conf. Ser., 2011, 276, 6-11.

11. K. M. Sandeep, S. Bhat, and S. M. Dharmaprakash, Appl. Phys. A Mater, 2016, 122, 1-9.

12. R. N. Chauhan, N. Tiwari, R. S. Anand, and J. Kumar, RSC Adv., 2016, 6, 86770-86781.

13. K. Prabakar, C. Kim, and C. Lee, Cryst. Res. Technol., 2005, 40, 1150-1154.

Publisher's Note Engineered Science Publisher remains neutral with regard to jurisdictional claims in published maps and institutional affiliations. 